\title{
Avaliação do consumo de água em torneiras em ambiente universitário
}

\author{
Evaluation of water consumption on taps at a university \\ campus
}

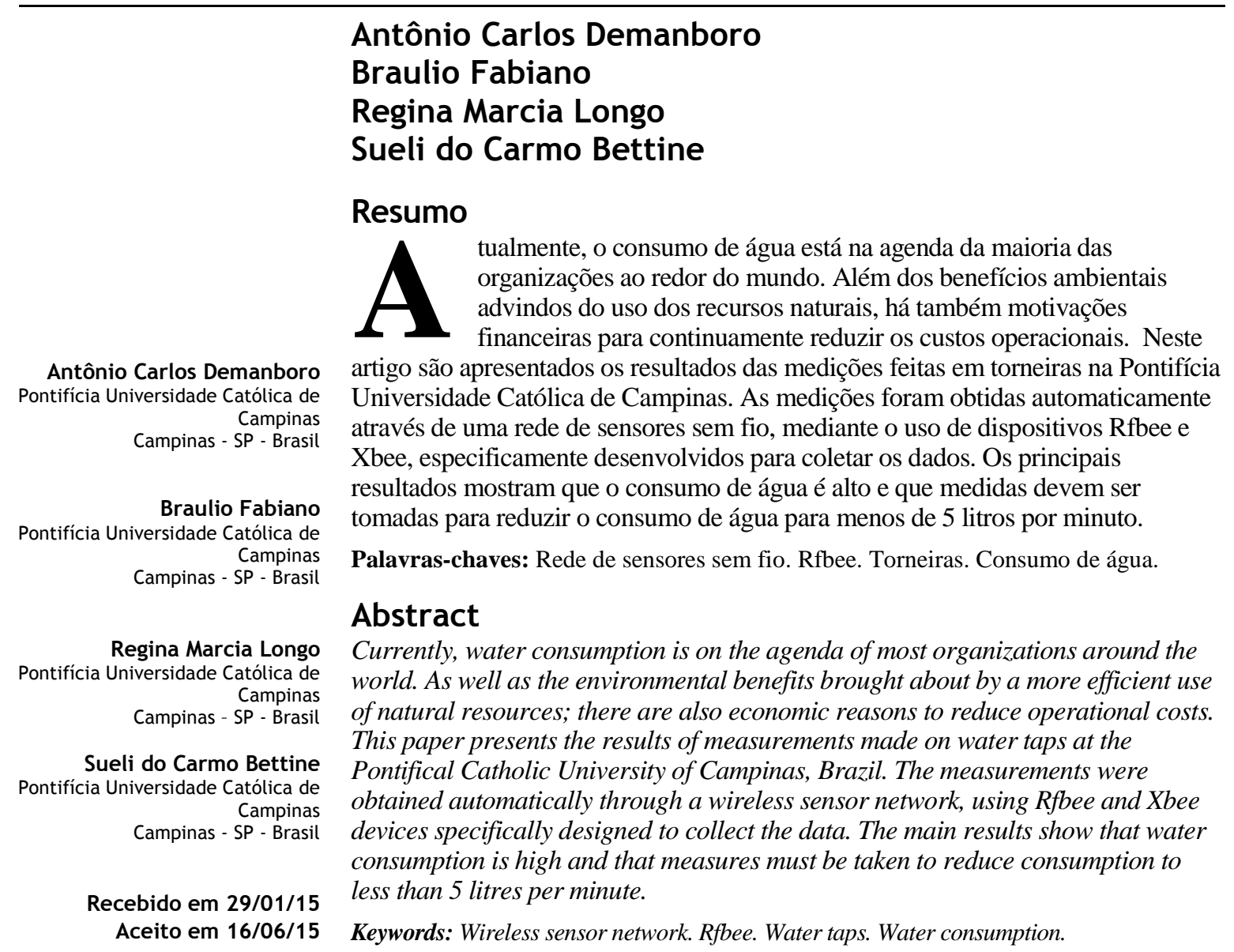




\section{Introdução}

O presente artigo apresenta a avaliação de dois dispositivos poupadores de água, uma torneira com acionamento por sensor e outra mecânica, tendo como premissa básica a necessidade de redução do consumo de água nos equipamentos hidrossanitários utilizados nos centros urbanos.

Parte-se da constatação de que os recursos hídricos na região de estudo, a bacia do rio Piracicaba, são escassos tanto em termos quantitativos como qualitativos. A bacia dispõe de $55,09 \mathrm{~m}^{3} / \mathrm{s}$ de vazão firme, enquanto no período de estiagem esse valor cai para $36,91 \mathrm{~m}^{3} / \mathrm{s}$. Segundo avaliações do Comitê das Bacias dos rios Piracicaba, Capivari e Jundiaí (COMITÊ..., 2013), a demanda prevista para 2020 é de $51,44 \mathrm{~m} 3 / \mathrm{s}$, o que tornará a situação ainda mais crítica.

Vê-se assim que medidas para a conservação de água são necessárias, como observaram Santos et al. (2006) em várias escalas:

(a) "macro", onde a ação é realizada em sistemas ambientais e bacias hidrográficas;

(b) "meso", referente ao abastecimento público de água e coleta de esgoto; e

(c) "micro", que se refere às edificações, objeto deste artigo.

Da mesma forma em que a quantidade de água não é distribuída igualmente em todo o território, seu consumo também é desigual. Isso ocorre devido a fatores culturais, climáticos, educacionais, econômicos, entre outros. A população consome em média 150 litros de água por dia, mas tais valores podem sofrer variação, já que em grandes centros urbanos o consumo de água pode chegar a valores maiores que 200 litros por dia, sem considerar as perdas nos sistemas de distribuição (COMITÊ..., 2013).

Alternativas para a diminuição do consumo de água tornam-se cada vez mais necessárias. Atitudes como captação de água das chuvas, uso de água não potável para lavagem, entre outros, tanto na área industrial como na comercial e residencial, podem promover redução na quantidade de água utilizada (SANTOS et al., 2006).

Nesse contexto, o uso de equipamentos poupadores de água tem papel de destaque na redução do consumo per capita de água.

Neste artigo aborda-se o consumo de água em torneiras por acionamento por sensor e mecânica, em ambiente universitário.

\section{Revisão bibliográfica}

A quantidade de água potável consumida por aparelhos sanitários depende de muitas variáveis e basicamente varia de acordo com o local e a época do ano em que estão sendo usados, além da instalação predial e das tecnologias envolvidas. A cultura e consequentemente seus hábitos também interferem no consumo de água (GONÇALVES, 2006).

O consumo, no entanto, pode ser abordado por dois aspectos. O primeiro é a tecnologia do aparelho sanitário, que envolve sua construção e funcionamento, determinando a vazão de água. Tem-se como exemplo uma torneira com características fixadas em norma técnica, que possui determinada vazão dependendo da pressão e da tubulação existente. Assim, a vazão varia com o número de voltas imposto ao volante responsável por sua abertura. Há, às vezes, um arejador na extremidade de saída, o que pode alterar substancialmente a vazão da água, enquanto o número de voltas do volante permanece o mesmo. Dessa forma, o uso de arejador faz com que o consumo de água seja menor, já que o jato "sólido" traz a mesma sensação de conforto, mas com menor quantidade de água (MENDONÇA, 2009; OLIVEIRA; ILHA; REIS, 2007).

No segundo, em relação à cultura, o comportamento é relevante e varia de acordo com cada indivíduo e o meio cultural em que está inserido. Aspectos individuais são os que determinam o número de voltas imprimidas ao volante, bem como o tempo de uso de uma torneira. No entanto, o grau de consciência sobre o valor da água vem aumentando devido a sua degradação e escassez, o que pode levar a mudanças nos padrões de comportamento (GONÇALVES, 2006).

No Brasil o uso de aparelhos economizadores de água vem crescendo de forma acelerada, com destaque para prédios de uso público, como shopping centers, teatros, cinemas, escolas, entre outros. O uso desses aparelhos é adotado por reduzir as despesas com água e esgoto, além de ganhar caráter ambiental, algo que cresce no país. Tais tendências também ocorrem nas edificações residenciais, principalmente nas populares, mas em menor escala (MENDONÇA, 2009; OLIVEIRA; ILHA; REIS, 2007).

Nesse sentido, Fasola et al. (2011) reportam economia de $48 \%$ através da substituição de torneiras automáticas por torneiras acionadas por sensor de presença em estudo realizado em duas 
escolas de Florianópolis, SC. No caso da substituição de torneira comum por torneira acionada por sensor, os autores relatam economia da ordem de $77 \%$.

Têm-se na Tabela 1, a seguir, a descrição dos principais aparelhos hidrossanitários economizadores de água disponíveis no mercado, de acordo com Gonçalves (2006).

A norma brasileira aplicável para torneiras comuns e de pressão de uso geral é a NBR 10281 (ABNT, 2003), que estabelece vazão mínima de $0,10 \mathrm{~L} / \mathrm{s}$ quando alimentada por água a uma pressão de 15 $\mathrm{kPa}$. Esses valores são considerados os mínimos necessários para a satisfação do usuário.

De acordo com a NBR 10281:2003, a vazão mínima para torneiras com arejadores é de 0,05 $\mathrm{L} / \mathrm{s}$, nas mesmas condições de uso sem arejador, o que faz com que a presença dele reduza a vazão em até $50 \%$.
O pulverizador é um dispositivo que, quando colocado na saída da torneira, faz com que seu jato seja transformado em jatos menores, semelhante ao que ocorre nos chuveiros, o que reduz a vazão para até $0,03 \mathrm{~L} / \mathrm{s}$, mas mantendo o conforto do usuário.

Para torneiras de lavatórios, válvulas de mictórios e registros de chuveiros, a norma aplicada é a NBR 13713 - Aparelhos hidráulicos acionados manualmente e com ciclo de fechamento automático (ABNT, 2009), que requisita um valor mínimo de vazão de torneiras, válvulas e registros. Esta norma é uma evolução da Norma 13713 (ABNT, 1996), que é apresentada na Tabela 2, a título de comparação.

A Norma 13713:2009 prevê valores máximos e mínimos, tanto para escoamento quanto para temporização. A Tabela 3 indica os parâmetros estabelecidos para funcionamento.

Tabela 1 - Torneiras disponíveis e principais características envolvidas

\begin{tabular}{l|l|l|l|l}
\hline \multicolumn{1}{c|}{ Tipo } & \multicolumn{1}{c|}{$\begin{array}{c}\text { Características } \\
\text { principais }\end{array}$} & \multicolumn{1}{c}{$\begin{array}{c}\text { Consumo } \\
\text { esperado }\end{array}$} & $\begin{array}{c}\text { Dispositivos } \\
\text { economizadores }\end{array}$ & Observações \\
\hline $\begin{array}{l}\text { Torneira } \\
\text { comum }\end{array}$ & Acionamento manual & $\begin{array}{l}\text { Variável com a } \\
\text { abertura }\end{array}$ & $\begin{array}{l}\text { Arejador, } \\
\text { pulverizador, } \\
\text { redutor de vazão }\end{array}$ & $\begin{array}{l}\text { 20\% do gasto da } \\
\text { residência }\end{array}$ \\
\hline $\begin{array}{l}\text { Torneira de } \\
\text { pressão }\end{array}$ & $\begin{array}{l}\text { Acionamento manual } \\
\text { Pressão mínima } 15 \mathrm{kPa}\end{array}$ & $\begin{array}{l}\text { Variável com a } \\
\text { abertura e } \\
\text { pressão }\end{array}$ & $\begin{array}{l}\text { Arejador, } \\
\text { pulverizador, } \\
\text { redutor de vazão }\end{array}$ & $\begin{array}{l}\text { Vazão min. 0,10 } \\
\text { L/s sem arejador } \\
\text { Com arejador } \\
\text { min. 0,05 L/s }\end{array}$ \\
\hline $\begin{array}{l}\text { Torneira de } \\
\text { fechamento } \\
\text { automático }\end{array}$ & $\begin{array}{l}\text { Acionamento } \\
\text { automático }\end{array}$ & $\begin{array}{l}\text { Constante por } \\
\text { ciclo }\end{array}$ & $\begin{array}{l}\text { Arejador, } \\
\text { pulverizador, } \\
\text { redutor de vazão }\end{array}$ & $\begin{array}{l}\text { Vazão min. 0,04 } \\
\text { L/s }\end{array}$ \\
\hline
\end{tabular}

Fonte: Gonçalves (2006).

Tabela 2 - Parâmetros estabelecidos na NBR 13713 (ABNT, 1996) - Aparelhos hidráulicos acionados manualmente e com ciclo de fechamento por acionamento por sensor

\begin{tabular}{l|c|c|c}
\hline \multicolumn{1}{c|}{ Tipo de aparelho } & $\begin{array}{c}\text { Vazão mínima de } \\
\text { funcionamento (L/s) }\end{array}$ & $\begin{array}{c}\text { Tempo máximo de } \\
\text { fechamento (s) }\end{array}$ & $\begin{array}{c}\text { Volume teórico de } \\
\text { consumo por uso (V) }\end{array}$ \\
\hline Torneira de lavatório & 0,05 & 15 & 0,75 \\
Válvula de mictório & 0,05 & 10 & 0,50 \\
Registro de chuveiro & 0,10 & 55 & 5,50 \\
\hline
\end{tabular}

Fonte: Oliveira, Itha e Reis (2007).

Tabela 3 - Parâmetros estabelecidos na NBR 13713 (ABNT, 2009)

\begin{tabular}{l|c|c|c|c}
\hline \multirow{2}{*}{$\begin{array}{c}\text { Tipo de aparelho acionado } \\
\text { mecanicamente }\end{array}$} & \multicolumn{2}{|c|}{ Tempo de ciclo (s) } & Vazão (L/s) & Volume máximo de \\
\cline { 2 - 5 } & Mínimo & Máximo & Mínima & água por ciclo (L) \\
\hline Válvulas para mictório & 4 & 10 & 0,07 & 1,5 \\
Válvulas para chuveiro & 18 & 50 & 0,10 & 12,5 \\
Aparelhos automáticos para lavatório & 4 & 10 & 0,04 & 1,2 \\
\hline Para aplicações/condições especiais & \multicolumn{3}{|c|}{ De acordo com as necessidades específicas } \\
\hline
\end{tabular}

Fonte: ABNT (2009). 


\section{Materiais e métodos}

Foram utilizados dois sensores de fluxo de água, que mediram as vazões de duas torneiras, uma com acionamento por sensor de presença e outra com acionamento mecânico (alavanca), ambas instaladas em um banheiro masculino situado no andar superior dos laboratórios do Campus I do Centro de Ciências Exatas, Ambientais e de Tecnologias (Ceatec) da Pontifícia Universidade Católica de Campinas. Os sensores utilizados foram do modelo RFBee v.1.1; foram escolhidos por possuírem a arquitetura do microcontrolador mais fácil para realizar a conexão com a maioria dos transdutores de vazão existentes no mercado. Além do microcontrolador, o RFBee possui transceptor CC1101, o qual pode ser programado na mesma IDE (Integrated Development Environment) do Arduino. O Arduino é uma plataforma que permite criar objetos eletrônicos interativos, licenciado segundo os termos da GNU Library or Lesser General Public License Version 2.0 (LGPLv2).

Para a programação do RFBee, utilizaram-se as bibliotecas disponíveis do Arduino. Essas bibliotecas possuem compartimentadas todas as funções em módulos, o que torna sua compreensão e o desenvolvimento de aplicações mais fáceis.

Quanto ao transdutor de vazão, foi utilizado para realizar a coleta de vazões das torneiras o $G \quad 1 / 2$ Walter Flow, sensor modelo POW110D3B. Tratase de um aparelho que gera pulsos a cada $28,5 \mathrm{~mL}$ (obtido por meio de testes de bancada).

Já a topologia da rede foi composta de dois nós, e nó sensor foi conectado aos transdutores de vazão, recebendo pulsos constantemente e armazenandoos quando as torneiras eram utilizadas. $\mathrm{O}$ nó base, por sua vez, foi conectado ao computador, requisitando os dados de vazão ao nó sensor, sendo respondidos por meio dos pulsos armazenados. Recebidos pelo nó base, os pulsos são retransmitidos ao computador, em que há a conversão em valores correspondentes em mililitros, armazenando-os em arquivos, com indicação da data e da hora em que foram recebidos. Dessa forma, é possível avaliar o volume utilizado a cada acionamento de cada uma das torneiras, concluindo qual apresenta menor consumo.

A coleta de dados foi realizada durante 2 meses, de abril a junho de 2013. Após o fim da coleta, os dados foram tabulados, e a partir dos valores obtidos calculou-se a vazão média a cada uso das torneiras. A Figura 1 apresenta o esquema básico de transmissão de dados.

\section{Resultados}

As medições foram realizadas em um banheiro masculino localizado no prédio do Centro Tecnológico da Pontifícia Universidade Católica de Campinas. As medições foram realizadas no período de abril a junho de 2013. Os dados foram separados mensalmente, medindo-se o volume de água e o tempo utilizado em cada acionamento. As torneiras diferiam em sua forma de uso: uma possuía acionamento mecânico (alavanca que permite controlar a vazão de água desejada), enquanto a outra era acionada por sensor de presença (aproximação da mão).

\section{Resultados obtidos para a torneira com acionamento por sensor de presença}

Têm-se nas Tabelas 4 a 6 os resultados obtidos com o uso de torneira com acionamento por sensor de presença.

\section{Resultados obtidos para a torneira mecânica}

Os resultados do uso da torneira mecânica podem ser visualizados nas Tabelas 7 a 9 .

Figura 1 - Nó sensor, que coleta e transmite os dados de vazão, e nó base, que recebe os dados e os transmite para o computador

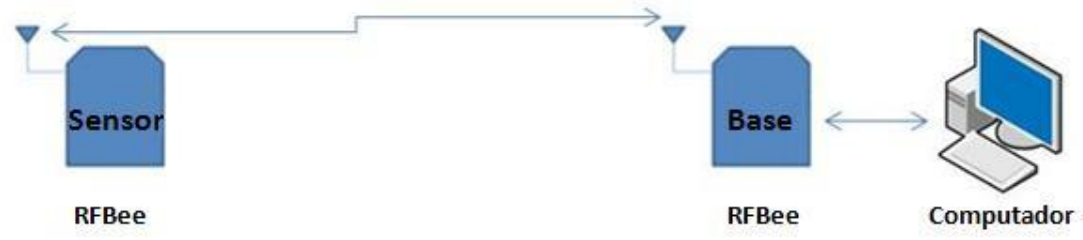

Fonte: Yano et al. (2014). 
Tabela 4 - Consumo da torneira acionada por sensor no mês de abril/2013

\begin{tabular}{c|c|c|c|c}
\hline Dia & $\begin{array}{c}\text { Volume } \\
\text { médio }(\mathbf{m L})\end{array}$ & $\begin{array}{c}\text { Tempo } \\
\text { médio }(\mathbf{s})\end{array}$ & $\begin{array}{c}\text { Vazão média } \\
(\mathbf{m L} / \mathbf{s})\end{array}$ & Acionamentos \\
\hline 17 & 445,41 & 6,7 & 66,48 & 7 \\
18 & 424,62 & 7,0 & 60,66 & 3 \\
19 & 648,38 & 7,5 & 86,45 & 10 \\
22 & 664,05 & 5 & 132,81 & 1 \\
23 & 908,34 & 8,9 & 102,06 & 7 \\
25 & 997,24 & 12,0 & 83,10 & 11 \\
26 & $1.175,15$ & 11,3 & 104,00 & 3 \\
29 & 594,7 & 6,0 & 99,12 & 3 \\
30 & $1.483,90$ & 13,3 & 111,57 & 3 \\
\hline Média & $\mathbf{8 1 5 , 7 5}$ & $\mathbf{8 , 6}$ & $\mathbf{9 4 , 8 5}$ & $\mathbf{5}$ \\
\hline
\end{tabular}

Tabela 5 - Consumo da torneira acionada por sensor no mês de maio/2013

\begin{tabular}{c|c|c|c|c}
\hline Dia & $\begin{array}{c}\text { Volume médio } \\
(\mathbf{m L})\end{array}$ & $\begin{array}{c}\text { Tempo } \\
\text { médio }(\mathbf{s})\end{array}$ & $\begin{array}{c}\text { Vazão média } \\
(\mathbf{m} \mathbf{L} / \mathbf{s})\end{array}$ & Acionamentos \\
\hline 2 & $1.005,61$ & 9,8 & 102,61 & 13 \\
3 & 781,60 & 7,8 & 100,21 & 4 \\
6 & $1.215,53$ & 11,5 & 105,70 & 2 \\
7 & $1.366,34$ & 12,6 & 108,44 & 5 \\
8 & 524,40 & 5,0 & 104,88 & 2 \\
9 & 844,08 & 8,8 & 95,92 & 6 \\
10 & $1.410,75$ & 12,0 & 117,56 & 2 \\
14 & 347,70 & 2,0 & 173,85 & 1 \\
15 & 937,91 & 8,7 & 107,81 & 11 \\
16 & 944,65 & 9,4 & 100,49 & 22 \\
20 & $1.044,81$ & 9,4 & 111,15 & 10 \\
21 & 954,39 & 9,4 & 101,53 & 25 \\
23 & 616,74 & 6,0 & 102,79 & 10 \\
24 & 617,87 & 7,2 & 85,82 & 5 \\
28 & 748,49 & 8,6 & 87,03 & 9 \\
\hline Média & $\mathbf{8 9 0 , 7 2}$ & $\mathbf{8 , 6}$ & $\mathbf{1 0 3 , 5 7}$ & $\mathbf{9}$ \\
\hline
\end{tabular}

Tabela 6 - Consumo da torneira acionada por sensor no mês de junho/2013

\begin{tabular}{c|c|c|c|c}
\hline Dia & $\begin{array}{c}\text { Volume médio } \\
(\mathbf{m L})\end{array}$ & $\begin{array}{c}\text { Tempo } \\
\text { médio }(\mathbf{s})\end{array}$ & $\begin{array}{c}\text { Vazão média } \\
(\mathbf{m L} / \mathbf{s})\end{array}$ & Acionamentos \\
\hline 3 & 929,10 & 9,0 & 103,23 & 2 \\
4 & 628,90 & 6,7 & 93,87 & 3 \\
5 & 994,93 & 10,0 & 99,49 & 2 \\
10 & 807,50 & 8,3 & 97,29 & 3 \\
11 & 864,51 & 8,8 & 98,24 & 6 \\
13 & $1.524,75$ & 17,0 & 89,69 & 1 \\
18 & 748,84 & 7,3 & 102,58 & 4 \\
\hline Média & $\mathbf{9 2 8 , 3 6}$ & $\mathbf{9 , 6}$ & $\mathbf{9 6 , 7 0}$ & $\mathbf{3}$ \\
\hline
\end{tabular}


Tabela 7 - Consumo da torneira mecânica no mês de abril/2013

\begin{tabular}{c|c|c|c|c}
\hline Dia & $\begin{array}{c}\text { Volume médio } \\
(\mathbf{m L})\end{array}$ & $\begin{array}{c}\text { Tempo } \\
\text { médio }(\mathbf{s})\end{array}$ & $\begin{array}{c}\text { Vazão média } \\
(\mathbf{m L} / \mathbf{s})\end{array}$ & Acionamentos \\
\hline 9 & 619,02 & 10,4 & 59,52 & 5 \\
10 & $1.308,86$ & 21,0 & 62,33 & 4 \\
16 & 409,26 & 7,2 & 56,84 & 5 \\
17 & 811,30 & 13,0 & 62,41 & 3 \\
18 & $1.057,35$ & 19,0 & 55,65 & 1 \\
19 & 625,24 & 9,0 & 69,47 & 7 \\
23 & 886,35 & 15,0 & 59,09 & 1 \\
24 & 890,34 & 15,0 & 59,36 & 5 \\
25 & 748,92 & 13,6 & 55,07 & 9 \\
26 & 511,51 & 8,1 & 63,15 & 7 \\
30 & 614,78 & 9,9 & 62,10 & 11 \\
\hline Média & $\mathbf{7 7 1 , 1 8}$ & $\mathbf{1 2 , 8}$ & $\mathbf{6 0 , 2 5}$ & $\mathbf{5}$ \\
\hline
\end{tabular}

Tabela 8 - Consumo da torneira mecânica no mês de maio/2013

\begin{tabular}{c|c|c|c|c}
\hline Dia & $\begin{array}{c}\text { Volume médio } \\
(\mathbf{m L})\end{array}$ & $\begin{array}{c}\text { Tempo } \\
\text { médio }(\mathbf{s})\end{array}$ & $\begin{array}{c}\text { Vazão média } \\
(\mathbf{m L} / \mathbf{s})\end{array}$ & Acionamentos \\
\hline 2 & 584,25 & 12,2 & 47,89 & 6 \\
3 & 388,41 & 5,7 & 68,14 & 7 \\
6 & $1.031,70$ & 17,3 & 59,64 & 3 \\
7 & 442,56 & 7,9 & 55,99 & 21 \\
9 & 851,98 & 14,5 & 58,76 & 17 \\
10 & $1.077,30$ & 23,0 & 46,84 & 1 \\
13 & 780,90 & 13,5 & 57,84 & 11 \\
14 & 599,22 & 10,7 & 56,00 & 23 \\
15 & 820,80 & 13,7 & 59,91 & 10 \\
16 & 948,38 & 16,2 & 58,54 & 25 \\
20 & 768,43 & 13,6 & 56,50 & 8 \\
21 & $1.369,17$ & 23,6 & 58,02 & 22 \\
22 & 895,61 & 14,8 & 60,51 & 4 \\
23 & 772,35 & 16,0 & 48,27 & 13 \\
27 & 577,13 & 13,0 & 44,39 & 2 \\
28 & 658,35 & 11,7 & 56,27 & 7 \\
\hline Média & $\mathbf{7 8 5 , 4 1}$ & $\mathbf{1 4 , 2}$ & $\mathbf{5 5 , 3 1}$ & $\mathbf{1 1}$ \\
\hline
\end{tabular}

Tabela 9 - Consumo da torneira mecânica no mês de junho/2013

\begin{tabular}{c|c|c|c|c}
\hline Dia & $\begin{array}{c}\text { Volume médio } \\
(\mathbf{m L})\end{array}$ & $\begin{array}{c}\text { Tempo } \\
\text { médio }(\mathbf{s})\end{array}$ & $\begin{array}{c}\text { Vazão média } \\
(\mathbf{m L} / \mathbf{s})\end{array}$ & Acionamentos \\
\hline 3 & $1.843,24$ & 31,0 & 59,46 & 4 \\
4 & 921,50 & 16,3 & 56,53 & 9 \\
5 & 779,95 & 12,7 & 61,41 & 3 \\
6 & $1.695,75$ & 29,5 & 57,48 & 2 \\
10 & 740,53 & 13,8 & 53,66 & 6 \\
11 & $1.115,30$ & 19,2 & 58,09 & 6 \\
12 & $1.640,18$ & 31,5 & 52,07 & 2 \\
13 & 811,91 & 14,9 & 54,49 & 16 \\
14 & 202,35 & 4,0 & 50,59 & 1 \\
17 & 466,45 & 7,7 & 60,58 & 3 \\
18 & $1.125,04$ & 18,8 & 59,84 & 4 \\
\hline Média & $\mathbf{1 . 0 3 1 , 1 1}$ & $\mathbf{1 8 , 1}$ & $\mathbf{5 6 , 9 7}$ & $\mathbf{5}$ \\
\hline
\end{tabular}

140 Demanboro, A. C.; Fabiano, B.; Longo, R. M.; Bettine, S. do C. 
Nas Tabelas 10 e 11, a seguir, são apresentados os valores mínimos e máximos dos volumes obtidos das medições realizadas, tanto para a torneira por acionamento por sensor como para a torneira mecânica. São apresentados os tempos medidos e calculada a vazão correspondente.

\section{Avaliação dos resultados}

Com base nos resultados obtidos da torneira por acionamento por sensor, tem-se que:

(a) a torneira acionada por sensor de presença foi, em média, utilizada 6 vezes ao dia e teve um total de 196 acionamentos ao longo de 31 dias de medições. O volume médio mensal utilizado por acionamento foi de $878,28 \mathrm{~mL}$, ou 0,9 L. Já o volume total utilizado no período foi de $175 \mathrm{~L}$. O tempo médio de acionamento foi de $9 \mathrm{~s}$. O tempo total de acionamento, por sua vez, foi de $29 \mathrm{~min}$. A vazão média do período medido foi de $98,37 \mathrm{~mL} / \mathrm{s}$ (0,10 L/s ou $5,9 \mathrm{~L} / \mathrm{min})$;

(b) a vazão mínima estabelecida pela NBR 13713 (ABNT, 2009) para aparelhos automáticos para lavatório, de $0,04 \mathrm{~L} / \mathrm{s}$ ou $40 \mathrm{~mL} / \mathrm{s}$, foi atendida em toda a série de medições realizadas. $\mathrm{O}$ volume máximo de água por ciclo, de 1,2 L, foi ultrapassado em média quatro vezes, embora os valores médios mensais obtidos, de $0,9 \mathrm{~L}$, sejam inferiores ao estipulado na norma. O tempo de ciclo se situou na faixa estabelecida, entre 4 s e 10 $\mathrm{s}$, ficando mais próximo do limite superior ( $9 \mathrm{~s} \mathrm{em}$ média);

(c) a vazão mínima estabelecida pela NBR 10281 (ABNT, 2003), de 0,05 L/s, para torneiras com arejadores não foi atendida no mês de abril, tendo apresentado o valor mínimo extremo, de $0,04 \mathrm{~L} / \mathrm{s}$ (Tabela 10);

(d) a vazão média máxima de 173,85 mL/s (10,4 $\mathrm{L} / \mathrm{min}$ ) foi obtida no dia 15 de maio e é muito superior ao valor máximo que se esperava obter, de $0,10 \mathrm{~L} / \mathrm{s}$ ou $6 \mathrm{~L} / \mathrm{min}$. Entretanto, na média, essa torneira trabalhou com uma vazão de $98,37 \mathrm{~mL} / \mathrm{s}$, ou $5,9 \mathrm{~L} / \mathrm{min}$; e

(e) os valores extremos (Tabela 10) permitem verificar a ocorrência de grande variação nos volumes utilizados, bem como nos tempos e vazões envolvidos, em decorrência das opções feitas pelos usuários.

Com base nos resultados obtidos para a torneira mecânica, tem-se que:

(a) a torneira mecânica foi, em média, utilizada 7 vezes ao dia e teve um total de 294 acionamentos ao longo de 38 dias de medições. O volume total utilizado foi de 240 L. O volume máximo de água por ciclo, normalizado em 1,2 L, foi ultrapassado em média cinco vezes, embora os valores médios mensais obtidos, de 0,8 L, sejam inferiores ao estipulado na norma. O tempo de ciclo médio foi de $15 \mathrm{~s}$. O tempo total de uso da torneira foi de $69,7 \mathrm{~min}$;

(b) a vazão mínima estabelecida pela NBR 10281 (ABNT, 2003), de 0,05 L/s, para torneiras com arejadores não foi atendida nos meses de abril e maio, tendo apresentado valores mínimos extremos de $0,01 \mathrm{~L} / \mathrm{s}$ e $0,03 \mathrm{~L} / \mathrm{s}$ respectivamente (Tabela 11);

(c) a vazão média máxima de $68,14 \mathrm{~mL} / \mathrm{s}$ (4 $\mathrm{L} / \mathrm{min}$ ) foi obtida no dia 15 de maio e é inferior ao valor máximo esperado, de $6 \mathrm{~L} / \mathrm{min}$. Na média, essa torneira trabalhou com uma vazão de 57,51 $\mathrm{mL} / \mathrm{s}$, ou 3,5 L/min; e

(d) os valores extremos (Tabela 11) permitem verificar a ocorrência de grande variação nos volumes utilizados, bem como nos tempos e vazões envolvidos, em decorrência da opção dos usuários.

Tabela 10 - Valores extremos devido ao uso da torneira acionada por sensor de presença

\begin{tabular}{c|c|c|c|c|c|c}
\hline Mês & $\begin{array}{c}\text { Volume } \\
\text { mínimo }(\mathbf{m L})\end{array}$ & $\begin{array}{c}\text { Tempo } \\
(\mathbf{s})\end{array}$ & $\begin{array}{c}\text { Vazão } \\
(\mathbf{m L} / \mathbf{s})\end{array}$ & $\begin{array}{c}\text { Volume } \\
\text { máximo } \\
(\mathbf{m L} \mathbf{)}\end{array}$ & $\begin{array}{c}\text { Tempo } \\
(\mathbf{s})\end{array}$ & $\begin{array}{c}\text { Vazão } \\
(\mathbf{m L} / \mathbf{s})\end{array}$ \\
\hline Abr & 153,90 & 4 & 42,75 & $2.225,85$ & 23 & 96,78 \\
Mai & 71,25 & 1 & 71,25 & $3.719,25$ & 31 & 119,98 \\
Jun & 416,10 & 5 & 83,22 & $1.524,75$ & 17 & 89,69 \\
\hline
\end{tabular}


Tabela 11 - Valores extremos devido ao uso da torneira mecânica

\begin{tabular}{c|c|c|c|c|c|c}
\hline Mês & $\begin{array}{c}\text { Volume } \\
\text { mínimo } \\
(\mathbf{m L})\end{array}$ & $\begin{array}{c}\text { Tempo } \\
(\mathbf{s})\end{array}$ & $\begin{array}{c}\text { Vazão } \\
(\mathbf{m L} / \mathbf{s})\end{array}$ & $\begin{array}{c}\text { Volume } \\
\text { máximo } \\
(\mathbf{m L})\end{array}$ & $\begin{array}{c}\text { Tempo } \\
(\mathbf{s})\end{array}$ & $\begin{array}{c}\text { Vazão } \\
(\mathbf{m L} / \mathbf{s})\end{array}$ \\
\hline Abr & 19,95 & 2 & 9,98 & $2.231,55$ & 36 & 61,99 \\
Mai & 25,65 & 1 & 25,65 & $4.836,45$ & 91 & 53,15 \\
Jun & 188,10 & 2 & 94,05 & $3.910,20$ & 65 & 60,16 \\
\hline
\end{tabular}

\section{Conclusão}

Os resultados obtidos entre as duas torneiras selecionadas permitem concluir que a torneira mecânica teve mais que o dobro de tempo total de acionamento que a torneira acionada por sensor, muito embora seu volume total tenha sido apenas $27 \%$ maior. Essa opção de uso pode ter sido influenciada pela proximidade entre o lavatório em que foi instalada a torneira mecânica e as bacias sanitárias existentes no local. Além disso, pelo fato de ser operada manualmente, o tempo de abertura e fechamento tende a ser maior, embora isso não se tenha refletido em uma vazão maior.

Desse modo, a torneira mecânica apresentou uma vazão média muito inferior àquela observada na torneira acionada por sensor $(3,5 \mathrm{~L} / \mathrm{min}$ contra $10,4 \mathrm{~L} / \mathrm{min}$ da torneira acionada por sensor).

O tempo médio de acionamento da torneira mecânica foi $70 \%$ superior ao da torneira acionada por sensor (15 s contra $9 \mathrm{~s}$ da torneira acionada por sensor).

Os volumes médios mensais foram praticamente iguais, sendo de $878,28 \mathrm{~mL}$ para a torneira acionada por sensor e ligeiramente inferior, de $862,57 \mathrm{~mL}$, para a torneira mecânica. Ressalta-se que os volumes médios obtidos pelo uso da torneira mecânica em abril e maio foram inferiores aos da torneira acionada por sensor, o que se inverteu no mês de junho.

Os valores extremos das vazões mostram uma tendência de menor vazão da torneira mecânica em relação à torneira por acionamento por sensor, tanto para as vazões mínimas como para as vazões máximas.

\section{Referências}

ASSOCIAÇÃO BRASILEIRA DE NORMAS TÉCNICAS. NBR 10281: torneira de pressão: requisitos e métodos de ensaio. Rio de Janeiro, 2003.

\section{ASSOCIAÇÃO BRASILEIRA DE NORMAS}

TÉCNICAS. NBR 13713: instalações hidráulicas prediais: aparelhos automáticos acionados mecanicamente e com ciclo de fechamento automático: requisitos e métodos de ensaio. Rio de Janeiro, 2009.

\section{ASSOCIAÇÃO BRASILEIRA DE NORMAS}

TÉCNICAS. NBR 13713: aparelhos hidráulicos acionados manualmente e com ciclo de fechamento automático. Rio de Janeiro, 1996.

COMITÊ DAS BACIAS HIDROGRÁFICAS DOS RIOS PIRACICABA, CAPIVARI E JUNDIAÍ. [Sobre]. Disponível em: <www.comitepcj.sp.gov.br>. Acesso em: 15 dez. 2013.

FASOLA, G. B. et al. Potencial de Economia de Água em Duas Escolas em Florianópolis, SC.

Ambiente Construído, Porto Alegre, v. 11, n. 4, p 65-78, out/dez. 2011.

GONÇALVES, R. F. Uso racional da água em edificações. Rio de Janeiro: Prosab/ABES, 2006.

MENDONÇA, T. R.Conservação de água em residências unifamiliares. 2009. Trabalho de Conclusão de Curso (Graduação em Engenharia Civil) - Escola de Engenharia, Universidade Federal de Sergipe, 2009.

OLIVEIRA, L. H. de; ILHA, M.; REIS, R. P. A. Água. PCC- USP, 2007. Disponível em: <http://pcc2540.pcc.usp.br/Material\%202007/Cap $\% 204 \% 20-\% 20$ Agua.pdf $>$. Acesso em: 12 out. 2013.

SANTOS, D. C. dos et al. Hierarquização de Medidas de Conservação de Água em Edificações residenciais Com o Auxílio da Análise Multicritério. Ambiente Construído, Porto Alegre, v. 6, n. 1, p. 31-47, jan-mar, 2006.

YANO, I. H. et al. Wireless Sensor Networks for Measuring Liquid Consumption in Economic Water Taps. American Journal of Applied Sciences, v. 11, n. 6, p. 899-905, 2014. 


\section{Agradecimentos}

Os autores agradecem à FINEP e à PUC-

Campinas, pelo apoio recebido na execução do

Projeto Finep/Ceatec-Hidro.

Antônio Carlos Demanboro

Faculdade Engenharia Ambiental, Programa de Pós Graduação em Sistemas de Infraestrutura Urbana | Pontifícia Universidade Católica de Campinas | Rod. D. Pedro I, km 136, Pq. Das Universidades, Campus I | Campinas - SP - Brasil | CEP 13086-900 | Tel.: (19) 3256-7370 |

E-mail: demanboro@puc-campinas.edu.br

\section{Braulio Fabiano}

Faculdade Engenharia Ambiental | Pontifícia Universidade Católica de Campinas | Rod. D. Pedro I, km 136, Pq. das Universidades Campinas | Campinas - SP - Brasil | CEP 13086-900 | Tel.: (19) 3343-7009 | E-mail: bfabiano@puc-campinas.edu.br

\section{Regina Marcia Longo}

Faculdade Engenharia Ambiental, Programa de Pós Graduação em Sistemas de Infraestrutura Urbana | Pontifícia Universidade Católica de Campinas | Tel.: (19) 3343-7518 | E-mail: regina.longo@puc-campinas.edu.br

\section{Sueli do Carmo Bettine}

Programa de Pós Graduação em Sistemas de Infraestrutura Urbana, Faculdade Engenharia Ambiental | Pontifícia Universidade Católica de Campinas | Tel.: (19) 3343-7518 | E-mail: subettine@puc-campinas.edu.br

\section{Revista Ambiente Construído}

Associação Nacional de Tecnologia do Ambiente Construído

Av. Osvaldo Aranha, $99-3^{\circ}$ andar, Centro

Porto Alegre - RS - Brasil

$$
\text { CEP } 90035-190
$$

Telefone: +55 (51) 3308-4084

Fax: +55 (51) 3308-4054

www.seer.ufrgs.br/ambienteconstruido

E-mail: ambienteconstruido@ufrgs.br 